\title{
Plantão pasicológico no CRAS em Poços de Caldas
}

Saulo Tavares Mota $\star$

Tommy Akira Goto ${ }^{\star}$

\begin{abstract}
Resumo
Acompanhando novas demandas, o Curso de Psicologia da PUC-Minas, campus Poços de Caldas, estabeleceu novas possibilidades de atuação e intervenção, rompendo barreiras do fazer clínico tradicional e indo em direção a uma concepção de "clínica-ampliada" a partir do Plantão Psicológico. Pretende-se aqui descrever a experiência dissidente de atendimento à população no formato de Plantão Psicológico num Centro de Referência da Assistência Social (CRAS), no municipio de Poços de Caldas. A experiencia proporcionou aos alunos um contato com alguns desafios de articular novas práticas em espaços insólitos do atuar do psicólogo, bem como a produção de conhecimento acerca dessas práticas.
\end{abstract}

Palavras-chave: clínica ampliada; psicólogos no CRAS; clínica-escola da PUC Minas.

\section{Psychological service in the CRAS in Poços de Caldas}

\begin{abstract}
Following further demands, the PsychologyUndergraduateProgram, at PUC-Minas campus Poços de Caldas, established new possibilities for action and intervention, breaking traditional barriers of clinical work and going toward a conception of "extended-clinic" through the psychological service. This paper intends to describe the dissident experience of serving the population at a psychological service format in a Reference Center for Social Welfare (CRAS), in the municipality of Poços de Caldas. The experience gave the students the opportunity to deal with some challenges to articulate new strategies at unusual areas of the psychologist's practice, as well as the production of knowledge about these practices.
\end{abstract}

Keywords: extended clinic; psychologists at CRAS; university clinic PUC Minas.

\footnotetext{
^ Graduação em psicologia pela Pontifícia Universidade Católica de Minas Gerais campus Poços de Caldas. Possui experiência de atuação na Secretaria Municipal de Assistência Social e no Centro de Referência da Assistência Social, além de intervenções psicossociais e socioanalíticas em grupos, organizações e instituições.

E-mail: saulo.psico@yahoo.com.br

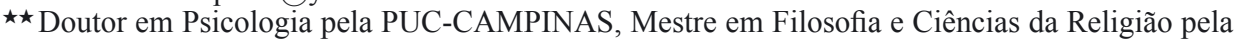
Universidade Metodista de São Paulo (2002) e graduado em Psicologia pela Universidade São Marcos. Atualmente é professor da PUC-Minas Gerais - Poços de Caldas e membro-colaborador da CLAFEN. Endereço: Pontifícia Universidade Católica de Minas Gerais, Departamento de Psicologia. Av. Padre Francis Cletus Cox, 1661 - Jd. Country Club. CEP: 37701-355 - Pocos de Caldas, MG - Brasil

E-mail: tommy.goto@pucpcaldas.br
} 


\section{UMA CONCEPÇÃO DE CLÍNICA-AMPLIADA: UMA MUDANÇA NECESSÁRIA}

A formação do profissional psicólogo no Brasil passa atualmente por mudanças epistemológicas e de atuação, sendo problematizada nos últimos anos sob uma nova ótica. Até meados de 1980, o modelo de formação do psicólogo foi calcado na noção de atuação da Psicologia Clínica, Escolar e Organizacional, sendo que, desde o início de suas atividades no país, os cursos de formação em Psicologia tiveram a primazia do pensar clínico em seu currículo.

Em uma pesquisa feita em 1987, conforme Ferreira Neto (2004), foi constatado que $55,3 \%$ dos profissionais em atividade no país atuavam na área clínica, e os cursos de especialização nesta mesma área tinham uma porcentagem correspondente a 51\%, em todo o país. Segundo o autor, esse espaço de atuação, denominado anteriormente de concepção clássica de clínica, respondia por um modelo específico - caracterizado por ser liberal e privado - que adota a perspectiva do atendimento em consultório particular e que é apontada como a área de atuação que produz maior índice de satisfação entre os profissionais. Isso se deu porque, de acordo com Ferreira Neto (2004, p. 89-90), a “[...] clínica tradicional possui um modelo mais homogêneo, largamente influenciado pelo modelo médico de atendimento."

Nesse sentido, entende-se aqui a clínica como uma instituição, ou seja, como um conjunto de normas, enunciados e valores sociais produzidos a partir da interação e articulação entre a ação histórica de indivíduos, grupos e coletividades, e a estrutura e normas sociais de um determinado momento. E, nessa perspectiva, podem ser classificados também como instituições: o matrimônio, o salário, o trabalho, a educação, a infância e a adolescência etc., assim como também a clínica (LOURAU, 2004).

Como afirma Ferreira Neto (2004), as mudanças de paradigmas na formação e na atuação do psicólogo partem muito mais das exigências das novas condições de trabalho do psicólogo no país, do que de reflexões de teóricos brilhantes. Dessa forma, foi ainda na década de 1980 que esse modelo de atuação e formação do psicólogo no Brasil começou a ser (re) pensado. Nesse momento, o país sofria serias modificações em nível social, político e econômico e, segundo Dimenstein (1998), foi nesse período que se observou um crescimento populacional acelerado, migrações internas, de maneira especial nos grandes centros urbanos, acarretando com isso uma expansão desordenada. Para essa mesma autora, tal situação crítica fez com que a assistência oferecida à população nos serviços de saúde fosse se deteriorando, apesar dos avanços tecnológicos alcançados na época.

Diante das novas exigências causadas pela situação crítica, o psicólogo não pôde mais limitar seus serviços à classe média e/ou alta, ao contrário, começou a se aproximar das camadas menos favorecidas da população, encontrando, assim, espaços, realidades e processos de subjetivação diferentes dos que estava anteriormente habituado. Esse movimento implicou muitas vezes na migração do psicólogo do modelo clínico tradicional ou clássico, que tem a perspectiva de atendimento em consultórios particulares como paradigma, para um modelo 
de atendimento "além muros do consultório", numa perspectiva de clínica-ampliada, promovida em ambientes e situações insólitas que fazem com que obrigatoriamente o profissional crie e desenvolva novos modelos de atendimento que contemplem as necessidades do novo campo de trabalho.

Uma atuação profissional consonante com a concepção de clínica ampliada considera pelo menos dois aspectos principais: o reconhecimento dos limites ontológicos dos saberes em relação à singularidade do sujeito, tendo vista que a generalização está condenada a ser parcial em toda situação singular (a classificação de patologias, por exemplo); e a criação e a produção de um projeto terapêutico que leve em conta as diferenças singulares de sujeito, tendo como base justamente os limites do "Universal" para se compreender o "Singular". Dessa forma, "[...] o que inicialmente é um limite do saber pode ser transformado em possibilidade prática de intervenção." (CUNHA, 2005, p. 97).

Com o intuito de acompanhar as exigências das novas condições de trabalho do profissional psicólogo na Brasil, bem como as demandas manifestadas, a Clínica-Escola do Curso de Psicologia da PUC Minas, campus Poços de Caldas - por meio de pesquisa na região para a elaboração do seu projeto político-pedagógico - estabeleceu novas possibilidades de atuação e intervenção para seus alunos-estagiários, rompendo com as barreiras do fazer clínico privado, "entre quatro paredes", partindo de uma concepção de "clínica-ampliada". Pretende-se neste trabalho, relatar tal experiência-intervenção bem como esclarecer os parâmetros e paradigmas que conduziram essa prática.

\section{Plantão PSicológico: uma experiênCIA AMPliada de Clínica}

O serviço de atendimento em Plantão Psicológico foi criado e aperfeiçoado ao longo dos anos. Sobre a expressão "Plantão", Mahfoud (1987) afirma que se trata de um serviço desempenhado por profissionais que, por um tempo determinado e ininterrupto, colocam-se à disposição de quaisquer pessoas que necessitem de seus serviços. Tal sistema demanda a disponibilidade para lidar com o não esperado e com a probabilidade de não mais encontrar com o cliente. Dessa forma, o serviço de plantão de psicólogos oferecido funciona como um espaço que "dá ouvidos" à demanda que não se enquadra nas prioridades definidas por casos mais graves e que, portanto, não estão de acordo com as especificidades dos atendimentos oferecidos pelos especialistas ou psiquiatras.

Pode-se dizer que a modalidade de atendimento denominada Plantão Psicológico teve seu início na década de 1960. Nessa época, em São Paulo, o Serviço de Aconselhamento Psicológico do Instituto de Psicologia da USP começava a oferecer um "plantão" de atendimento ao público. Na década de 1980, o Centro de Desenvolvimento da Pessoa, integrante do Instituto Sedes Sapientiae ofereceu à comunidade um Plantão de Psicólogos. As premissas principais deste serviço eram: atendimento imediato ao cliente, sem a necessidade de agendamento prévio, atendimento ao cliente em no máximo três seções, porém, sem substituir a psicoterapia, e caracterizava cada seção como um universo único. 
Tais premissas do serviço de Plantão Psicológico foram também adotadas pela Clínica-Escola do Curso de Psicologia da PUC Minas, campus de Poços de Caldas, de tal forma que se conseguiu um formato de atendimento mais fluido e que eliminou em grande parte as filas de espera que geralmente se pode encontrar em serviços públicos à população de massa, situação na qual um problema simples pode se agravar.

Desde sua gênese, a proposta do Plantão Psicológico é que os profissionais envolvidos estejam em sintonia com a Abordagem Centrada na Pessoa (ACP) formulada inicialmente por Carl Rogers, apesar de também ser definida por outras abordagens que pense o profissional totalmente à disposição de acolher a experiência do cliente em determinada situação, em vez de enfocar o seu problema. Tal abordagem define seu foco a partir do referencial do cliente e não pela especialização do profissional, se referindo dessa forma, à possibilidade de responder à pessoa que coloca sua demanda, já no momento presente, no momento atual da situação de encontro. Dessa forma, é possível que o atendimento no formato de Plantão Psicológico aconteça de forma fluida, e em consonância com os pressupostos da clínica-ampliada, paradigma que rege os fazeres da Clínica Escola da PUC Minas de Poços de Caldas, já que recebe a pessoas sem um modelo de atendimento a priori, e com um olhar desprovido de normas, isento da necessidade de trabalhar para a manutenção do status quo.

\section{Diretrizes para atuaÇão no Centro de Referência da Assistência Social}

O Centro de Referência da Assistência Social (CRAS) é uma unidade de Proteção Social Básica prevista na Política Nacional de Assistência Social. A política de Proteção Social tem por objetivo prevenir situações de risco por meio do desenvolvimento de potencialidades e aquisições, do fortalecimento de vínculos familiares e comunitários, sendo que seus programas, projetos, serviços e benefícios destinam-se à população que apresenta situação de vulnerabilidade social decorrente da pobreza, privação e/ou fragilização de vínculos afetivos etc. (BRASIL, 2006). Ainda, o CRAS é uma unidade pública estatal, que tem a responsabilidade de oferecer serviços continuados de proteção social básica de assistência social às famílias, grupos e indivíduos em situação de risco social, sendo também uma unidade de referência e contrarreferência do usuário na rede de atendimentos do Sistema Único de Assistência Social (SUAS).

Procedendo dessa maneira, o CRAS torna-se também uma unidade que organiza a vigilância social e concretiza o direito de acesso a serviços de proteção básica dos cidadãos, dando ênfase aos territórios de referência (instalando unidades em regiões estratégicas do município). Para tanto, fica a cargo do município se ocupar identificar os territórios de vulnerabilidade social e neles implantar os CRAS, de tal forma que estes sejam instalados em locais de maior acessibilidade, para que a equipe possa se deslocar com facilidade e assim cobrir as áreas de vulnerabilidade.

Estando classificado como município de grande porte (de 100.001 a 900.000 habitantes), Poços de Caldas deve ter no mínimo quatro CRAS, sendo que, em que cada um, deve contar com uma equipe mínima para a execução dos serviços 
e ações necessariamente ofertados. A equipe deve ser formada por profissionais, preferencialmente do mesmo município, e dividida por categoria profissional. Essa equipe deve contar com pelo menos um(a) assistente social, um(a) psicólogo(a), um(a) auxiliar administrativo(a), quatro estagiários(as) e um(a) coordenador(a), e, com exceção dos estagiários, é sugerido que a carga horária de cada profissional seja de 40 horas semanais. Dentre outras coisas, é esperado desses profissionais que tenham a capacidade de executar procedimentos para escuta qualificada individual ou coletiva, de tal maneira que possam identificar necessidades, oferecer orientações, agenciar serviços e recursos para atendimento, encaminhamento e acompanhamento de famílias e indivíduos, e devem fundamentar seus fazeres em pressupostos teórico-metodológicos e ético-políticos (BRASIL, 2006).

Quanto à admissão de estagiários é previsto que serão aceitos graduandos dos cursos de Serviço Social e Psicologia. Ainda que com caráter pedagógico e com função específica de estagiário, é proposto que estes tenham um papel ativo e profissional no atendimento à população. Cabe, então, à Secretaria Municipal de Assistência Social (SEMAS), buscar firmar convênio com instituições de ensino superior para a inclusão de estagiários na equipe de trabalho do CRAS, já que existe a imposição de estágios supervisionados (BRASIL, 2006).

Atuando juntamente com outro profissional ou mesmo sozinho, desde que com supervisão, os estagiários poderão exercer funções como: atender, orientar, visitar famílias e indivíduos; realizar atividades em grupo; identificar e articular serviços da rede publica; e ser agente no processo de referência e contrarreferência, elaborando relatórios e informando os responsáveis pela referência sobre os clientes atendidos. Esses estágios devem contemplar as referências técnicas para atuação do psicólogo no CRAS previstos pelo Conselho Federal de Psicologia (CFP), que por meio do Centro de Referência Técnica em Psicologia e Políticas Públicas (CREPOP), propõe que o psicólogo, como trabalhador da Assistência Social, deve estar comprometido com a transformação social tomando como foco as necessidades, potencialidades, objetivos e experiências da população, de tal forma que contribua considerando e atuando sobre a dimensão subjetiva dos indivíduos, favorecendo o desenvolvimento de sua autonomia.

Nesse sentido, como observa CREPOP, as práticas em Psicologia não devem estar pautadas na categorização, patologização e objetificação das pessoas atendidas, mas na busca de compreender e intervir sobre os processos e recursos psicossociais, estudando as particularidades e circunstâncias em que ocorrem. Assim entende-se que no processo de enfrentamento das diversas situações da vida, as experiências, as condições de vida e os significados construídos ao longo do processo de desenvolvimento estão em jogo. De tal forma que, para se romper com os processos de exclusão e de marginalização, é importante que a pessoa assuma uma posição de construtora do seu próprio direito e da satisfação de suas necessidades. Por isso,

Os cidadãos devem ser pensados como sujeitos que têm sentimentos, ideologias, valores e modos próprios de interagir com o mundo, constituindo uma subjetividade que se constrói 
na interação contínua dos indivíduos com os aspectos históricoculturais e afetivo-relacionais que os cercam (CONSELHO FEDERAL DE PSICOLOGIA, 2007. p. 18).

Visto isso, a SEMAS de Poços de Caldas firmou um contrato de estágio com a Clínica-Escola do Curso de Psicologia da PUC Minas, permitindo que inicialmente quatro estagiários fizessem atendimentos no CRAS da zona sul do município, desde 2007. A Clínica-Escola por sua vez, tendo em vista que o estágio nesse espaço de atuação emergente e novo é de fundamental importância para a sua consolidação, enquanto possibilidade de atuação do psicólogo, bem como para a formação dos graduandos que serão os futuros profissionais requisitados nesse contexto, e em outros espaços similares, se comprometeu em oferecer a devida supervisão aos estagiários, bem como o apoio e acompanhamento das atividades feitas por eles no local de estágio.

\section{Uma eXPeriência de atendimento no CRAS do município de Poços de Caldas}

Logo após o estabelecimento do convênio entre PUC Minas e Prefeitura Municipal de Poços de Caldas, uma reunião entre estagiários, supervisor e equipe de trabalho do CRAS foi realizada a fim de que fossem estabelecidos os procedimentos da atuação em conjunto das duas equipes.

A equipe de trabalho do CRAS era composta por uma assistente social, coordenadora do CRAS, e um psicólogo, sendo que a equipe de estagiários era composta por quatro graduandos de Psicologia. Na reunião, foi determinado que as segundas e quartas-feiras os estagiários fizessem atendimento ao público, estando à disposição da comunidade das 14:00 às 17:00h, sendo que a equipe do CRAS estaria atendendo o público às terças e quintas-feiras das 08:00 às 12:00h e das 13:00 às 17:00h.

Assim, foi designado que os estagiários atuariam no CRAS da zona sul, no bairro Conjunto Habitacional. Essa medida foi tomada em virtude de o município de Poços de Caldas estar dividido em quatro regiões para que a população seja melhor atendida, de tal forma que se contemple o princípio de descentralização dos serviços. O espaço físico de que a SEMAS dispunha para colocar em funcionamento o CRAS era anteriormente de posse do centro administrativo do bairro. Nesse centro, foram disponibilizadas duas salas para os atendimentos e demais atividades do CRAS. As duas salas pequenas, após reforma, foram transformadas em uma sala de porte médio, e foi possível que se realizasse reuniões em grupos, possibilitando maior conforto para a comunidade. O estabelecimento como um todo é composto ainda por dois pátios, um refeitório, uma cozinha e duas salas (administração).

Ainda que para algumas atividades a reforma no espaço do CRAS tenha contribuído de forma eficaz, para os atendimentos psicológicos realizados pelos plantonistas ela veio "em má hora". Após a união das duas salas para a obtenção de uma maior, as condições para a realização de dois atendimentos simultâneos ficaram precárias: a sala fazia eco e a privacidade do cliente $^{1}$ foi defasada, já que além do som, o cliente podia ser visto por qualquer pessoa que passasse 
pela sala. Uma alternativa encontrada, ainda que parcialmente eficaz, foi colocar um biombo que ficava localizado na cozinha, para "separar a sala em duas", atenuando o problema de privacidade do cliente, ainda que em relação à sonoridade, este não sentisse efeitos acentuados.

Sobre a maneira como foram realizados os atendimentos, ficou estabelecido que nos dias de atendimento da equipe de profissionais do CRAS, os atendimentos psicológicos a serem realizados seriam marcados pelos estagiários. Para o controle de presença, havia um caderno no qual a assistente social marcava o nome das pessoas e o horário em que seriam atendidas, de tal forma que foi então possível ter o controle de presença e falta das pessoas, já que cada estagiário marcava em frente ao nome de cada cliente sua presença ou ausência.

Ainda que para ser atendida cada pessoa tivesse que passar pela assistente social, a espera não passava de três dias. Contudo, no início dos atendimentos houve casos de pessoas que esperaram duas semanas. Tal espera prolongada se deu em razão de haver apenas quatro estagiários que atendiam no máximo três clientes por semana cada um, sendo um total de doze pessoas atendidas por semana. Além disso, entre supervisor e estagiários ficou estabelecido que, sendo o atendimento na modalidade de plantão psicológico, cada cliente teria em média três atendimentos de até 50 minutos cada, sendo possível que se prolongasse esse prazo. Cada cliente teria direito a uma falta, sendo que duas faltas seguidas, sem justificativa, implicavam no fechamento do caso. Possíveis atrasos no atendimento à população tiveram também ligação com esse fato.

Outro fator a ser destacado é a questão das faltas e/ou desistências. Foram frequentes as faltas nos atendimentos psicológicos e muitas podem ser as razões atribuídas a esse fato. Primeiramente, pela dificuldade em comparecer nos horários marcados, às segundas e quartas-feiras à tarde. Muitas mulheres alegavam que trabalhavam nos horários marcados, de tal maneira que a incongruência dos horários foi um fator complicador que provocou desistências. Além disso, outro fator que possivelmente esteve ligado às faltas foi a ausência da cultura do uso de tais serviços, ou seja, a ausência da atribuição de valor ao serviço prestado já que não há conhecimento ou hábito de uso ou procura por serviços de atendimento psicológico pela comunidade atendida. Entende-se que essa experiência de atendimento psicológico oferecido à comunidade é de caráter fundamental para a criação e disseminação de uma cultura de prevenção e promoção de saúde, na qual a procura por serviços de saúde não esteja ligada a uma postura curativa, emergencial, medicamentosa, mas ao hábito do contínuo cuidado, individual e coletivo, do bem-estar físico, social e psicológico.

Quanto às demandas levantadas a partir do trabalho dos plantonistas pôde-se enfatizar algumas que se fazem relevantes no que diz respeito à possibilidade de planejamento de projetos de intervenção futuros. Dentre elas, pôdese destacar as queixas e as dificuldades nos relacionamentos familiares, sejam problemas conjugais, sejam problemas relacionados à educação ou ao relacionamento afetivo com os filhos. Atrelados a esses, estavam problemáticas com drogas, alcoolismo e gravidez precoce. 
Houve ainda questões relacionadas a doenças sexualmente transmissíveis. Quanto a essas, e outras relacionadas, o processo de atendimento em plantão psicológico precisou ser desempenhado sob dois vetores. O primeiro, privilegiando a redução da angústia e da tensão do cliente, por meio do acolhimento e relação de cuidado dos conteúdos trazidos pelo cliente, e o segundo em forma de orientação, de tal maneira que a pessoa estivesse instrumentalizada para posteriores tomadas de posição. No segundo semestre do ano de 2007, foram realizados 13 atendimentos ao público usuário do CRAS da região sul de Poços de Caldas, sendo que em 2008, esse número já ultrapassou 17 atendimentos.

\section{ConsideraÇões FinAis}

É possível afirmar que essa experiência de estágio contemplou várias das diretrizes e orientações para a atuação do psicólogo no CRAS. No que diz respeito às orientações técnicas para funcionamento do CRAS propostas pelo Ministério do Desenvolvimento Social e Combate à Fome, o estágio de atendimento em plantão psicológico corroborou com a exigência mínima de composição da equipe de atuação do CRAS. Quatro estagiários estiveram à disposição da comunidade durante o ano de 2007, no CRAS da zona sul, sendo que sua performance esteve em consonância com as diretrizes de atuação do psicólogo no CRAS propostas pelo Conselho Federal de Psicologia.

Foi necessário que cada plantonista considerasse seus clientes como pessoas que têm "[...] sentimentos, ideologias, valores e modos próprios de interagir com o mundo [...]", considerando que sua subjetividade está em constante construção e transformação devido à sua interação com os aspectos e elementos histórico-culturais e afetivorrelacionais que os circundam (CONSELHO FEDERAL DE PSICOLOGIA, 2007, p.18). Dessa forma, a própria interação e/ou intervenção do plantonista na vida de cada cliente, deve ser tomada como um vetor de construção e produção da subjetividade de cada sujeito. Algumas demandas trazidas pelos clientes colocaram por vezes os plantonistas em "xeque", já que a constituição e o estilo de vida de cada um apresentam peculiaridades e características que causam impasses éticos e políticos nos momentos de intervenção e compreensão. Além disso, a própria escolha do Plantão Psicológico como modalidade de atendimento pôde contemplar tais peculiaridades do público atendido. Isso significa um salto em direção à compreensão e à consolidação de serviços que priorizem a singularidade de cada cidadão que procura um serviço gratuito de atendimento ao público, já que se buscou "[...] compreender a demanda dos usuários, em seus aspectos históricos, sociais, pessoais e contextuais, para se realizar uma intervenção psicológica mais efetiva e resolutiva." (CONSELHO FEDERAL DE PSICOLOGIA, 2007.p.19).

Ainda que uma pequena parcela da comunidade da zona sul da cidade de Poços de Caldas tenha sido atendida pelos plantonistas no CRAS, as demandas levantadas poderão ser subsídios aptos para novas intervenções que contemplem as problemáticas inerentes à comunidade em questão sem perder de vista a singularidade de cada pessoa, família e grupo social. 


\section{Notas}

${ }^{1}$ Termo usado pelos(as) plantonistas designado às pessoas por eles(as) atendidas.

\section{REFERÊNCIAS}

BRASIL. Ministério do Desenvolvimento Social e Combate à Fome. Proteção básica do Sistema Único de Assistência Social: orientações técnicas para o Centro de Referência de Assistência Social. (Versão preliminar). Brasília-DF: Secretaria Nacional de Assistência Social, 2006.

CONSELHO FEDERAL DE PSICOLOGIA. Centro de Referência Técnica em Psicologia e Politicas Públicas: referências técnicas para atuação do(a) psicólogo(a) no CRAS/SUAS. Brasília, 2007.

CUNHA, G. T. A construção da clínica ampliada na atenção básica. São Paulo: Hucitec, 2005.

DIMENSTEIN, M. D. B. O Psicólogo nas Unidades Básicas de Saúde: desafios para a formação e atuação profissionais. Estudos de Psicologia, Natal, v. 3, n. 1, jan./jun. 1998. p. 53-81. Disponível em: <http://www.scielo.br/scielo. php script $=$ sci_arttext\&pid $=$ S1413-294X1998000100004\&lng=pt\&nrm=iso $>$. Acesso em: 4 jull. 2007.

FERREIRA NETO, J. L. A formação do psicólogo: clínica, social e mercado. São Paulo: Escuta, 2004.

LOURAU, R. Objeto e método da análise institucional. In: ALTOÉ, S. (Org.). René Lourau: Analista institucional em tempo integral. São Paulo: Hucitec, 2004. p. 66-86

MAHFOUD, M. Vivência de um desafio: plantão psicológico. In: ROSENBERG, R. L. (Org). Aconselhamento psicológico centrado na pessoa. São Paulo: EPU, 1987. p. 75-83.

Recebido em: janeiro de 2009

Aceito em:setembro de 2009 